\title{
Produção e composição química da macela em função da época de colheita ${ }^{1}$
}

\author{
Antonio Marcos Esmeraldo Bezerra²; Sebastião Medeiros Filho²; Lincoln Davi M de Oliveira³; Edilberto \\ R Silveira ${ }^{3}$

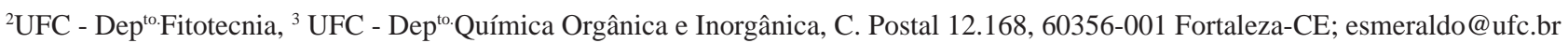

\section{RESUMO}

A macela é uma planta medicinal com efeitos antidispépticos, antidiarréicos e hepatoprotetores. Sua colheita deve conciliar a máxima produção de biomassa com o(s) maior(es) teor(es) de princípio(s) ativo(s). Neste trabalho, avaliou-se a influência da época de colheita nos componentes de produção e composição química, quantitativa e qualitativa da macela. Os tratamentos consistiram de sete colheitas (75; 85; 95; 105; 115; 125 e 135 dias após o transplantio (DAT)), dispostas em blocos ao acaso, com quatro repetições e parcelas com duas plantas na área útil (1,0 x 0,5 m). A época de colheita influenciou os componentes de produção e o teor dos princípios ativos da macela. Constatou-se acúmulo crescente de biomassa, mais expressivo no caule e folhas do que nas raízes, no decurso das colheitas. A produção de capítulos nas três últimas colheitas (2,6; 3,4 e $6,7 \mathrm{t} \mathrm{ha}^{-1}$ ) foi superior às demais. Os índices de colheita (relação entre a massa seca dos capítulos e a massa seca da parte aérea) nessas mesmas colheitas foram 47, 46 e 48\%. A parte aérea (caule e folhas) e os capítulos apresentaram maior rendimento dos extratos etanólico (REE) e clorofórmico (REC) do que as raízes. REE e REC variaram no transcurso da fase reprodutiva da planta, com picos 105 DAT (raízes: 0,17 g planta-1 ${ }^{-1}$ para REC), 125 DAT (capítulos: 3,92 e 18,02 g planta $^{-1}$ para respectivamente REE e REC; raízes: 0,34 g planta $^{-1}$ para REE) e 135 DAT (parte aérea: 3,02 e 11,70 g planta ${ }^{-1}$ para respectivamente REE e REC). O rendimento do óleo essencial apresentou valor máximo $135 \mathrm{DAT}\left(44,4 \mathrm{~L} \mathrm{ha}^{-1}\right)$. Os teores de acetato de trans-pinocarveíla nos capítulos situaram-se no intervalo de 52,3 a 73,5\%, entre as colheitas realizadas de 75 a 95 DAT, estabilizando-se em torno de 53,3\% nas colheitas seguintes. O teor de acetato de mirtenila nos capítulos manteve-se estável ao longo das colheitas

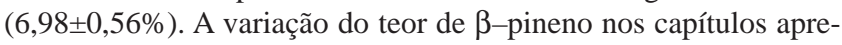
sentou dois patamares: $31,8 \pm 1,72 \%$ (de 85 a 105 DAT) e $49,2 \pm 1,15 \%$ (115 a 135 DAT).

Palavras-chave: Egletes viscosa (L.) Less., planta medicinal, óleo essencial, extrato etanólico, extrato clorofórmico.

\section{ABSTRACT \\ Production and chemical composition of macela as a result of the harvesting dates}

Macela (Egletes viscosa (L.) Less.) is a medicinal herb that possesses antidyspeptic, antidiarrheic, and hepatic protecting properties. Its harvest should allow assembling large biomass production and high yield of active principles. The main goal of this work was to evaluate the influence of harvesting dates over both biomass components and qualitative and quantitative chemical composition of macela. Treatments corresponded to seven harvesting dates (75; 85; 95; 105; 115; 125 and 135 days after the transplant (DAT)), displayed in a randomized blocks design, with four replications, and two useful-plant plots $(1.0 \times 0.5 \mathrm{~m})$. Harvesting dates affected both yield components and the content of active principles in macela. Biomass production showed a mounting increase during harvests, especially in stem and leaves. Capitulum production in the last three harvests (2.6; 3.4; and $6.7 \mathrm{t} \mathrm{ha}^{-1}$ ) surpassed the previous ones. The harvesting indexes (ratio between capitulum and aboveground dry mass) to the same periods were 47,46 and $48 \%$, respectively. Aboveground (stem and leaves) and capitulum had a higher yield of both ethanolic (YEE) and chloroformic (YCE) extracts than roots. YEE and YEC varied throughout plant reproductive phase, with peaks at 105 DAT (roots: 0.17 g plant $^{-1}$ for YEC); 125 DAT (flower buds: 3.92 and 18.02 g plant $^{-1}$ for respectively YEE and YEC; roots: 0.34 g plant $^{-1}$ for YEE), and 135 DAT (aboveground part: 3.02 and 11.70 g plant $^{-1}$ respectively for YEE and YEC). The yield of essential oil reached the maximum value at $135 \mathrm{DAT}$ (44.4 L ha-1). The content of trans-pinocarveyl acetate in the capitulum ranged from 52.3 to $73.5 \%$ in harvests from 75 to 95 DAT, remaining constant around $53.3 \%$ after that. The content of mirtenila acetate remained stable throughout harvests $(6,98 \pm 0,56 \%)$. The content of â-pineno in capitulum fluctuated in two steps: $31.8 \pm 1.72 \%$ (from 85 to 105 DAT), and $49.2 \pm 1.15 \%$ (from 115 to 135 DAT).

Keywords: Egletes viscosa (L.) Less., medicinal herb, essential oil, ethanolic extract, chloroformic extract.

\section{(Recebido para publicação em 22 de outubro de 2006; aceito em 20 de fevereiro de 2008)}

\begin{abstract}
A macela (Egletes viscosa (L.) Less.) é uma planta herbácea, anual, de caule cespitoso, toda pilosa, glandulosa, com folhas pinatífidas, de $2-5 \mathrm{~cm}$ de comprimento e subpecioladas. Possui capítulos florais solitários, curtopedunculados, dispostos em corimbos axilares e terminais com invólucro largo campanulado, brácteas pilosas, lanceoladas e agudas; a corola é alvo-
\end{abstract}

ligulada, lanceolada e aguda. O aquênio é quadrangular, de ápice denteado, com papus coroniforme e consistência carnosa (Corrêa, 1984; Barroso et al., 1991; Lorenzi \& Matos, 2002). Habita toda a América tropical, incluindo o Brasil, onde ocorre, de preferência, em locais inundáveis da planície interiorana, às margens de pequenas lagoas e riachos, do Piauí até Mato Gros- so (Matos, 2000). Estudos químicofarmacológicos com os capítulos florais dessa espécie, realizados na Universidade Federal do Ceará, a partir do fim da década de 80, comprovaram seus efeitos antidispépticos, antidiarréicos e hepatoprotetores, bem como a existência de dois quimiotipos caracterizados pela presença de acetato de transpinocarveíla (quimiotipo A) e acetato de

${ }^{1}$ Parte da tese apresentada à UFC para obtenção do título de doutor em Agronomia. 
cis-isopinocarveíla (quimiotipo B), no óleo essencial (Silveira \& Pessoa, 2005).

A colheita de plantas medicinais e aromáticas tem certas particularidades que a torna diferente das outras culturas, uma vez que objetiva conciliar a máxima produção de biomassa com o(s) maior(es) teor(es) de princípio(s) ativo(s). Assim, a determinação da época ideal de colheita varia de acordo com o órgão da planta, estádio de desenvolvimento e a época do ano (Corrêa Júnior et al., 1991; Martins et al., 1995). Neste sentido, Martins et al. (1995) enfatizam o empirismo existente no que se refere à determinação do momento adequado para colheita de plantas medicinais e aromáticas, enquanto Von Hertwig (1991) recomenda, nas espécies de alto valor comercial, a coleta de amostras espaçadas no tempo, para realização de análises, que identificarão o maior teor de princípios ativos ou o momento propício da colheita.

O indicativo da época ideal de colheita de espécies medicinais produtoras de flores é bastante variável, coletando-se desde botões florais, ainda fechados, como em Arnica montana Hook.; semi-abertos, em malva (Malva sylvestris L.), e até flores completamente abertas, como em Chamomilla recutita (L.) Rauschert, (Mattos, 1996). Portanto, deve-se levar em conta os teores de princípios ativos presentes nas estruturas reprodutivas.

A colheita de espécies produtoras de flores ou inflorescências requer elevado contingente de mão-de-obra braçal (Mattos, 1996). Para a colheita dos capítulos florais da macela, efetua-se o arranque das plantas, retira-se a terra que fica aderida às raízes, secam-se as plantas inteiras, natural ou artificialmente, destacam-se os capítulos da planta e fazse a separação das impurezas remanescentes na massa de capítulos manualmente ou em separador pneumático. Moreira et al. (2002) verificaram que, para colheita de 1,0 ha de macela, com produção estimada de 5,4 toneladas de capítulos, são requeridos, respectivamente, 3.275 e 2.033 DH (dias-homem) ha-1 para operação de retirada dos capítulos das plantas secadas de forma natural, ao sol, por cinco dias, em ambiente com cobertura de vidro, ou artificial, em secador elétrico a $40^{\circ} \mathrm{C}$ por cinco dias. Por sua vez, asseguram os autores, se o produtor optar pelo beneficiamento manual, consumirá 8.717 DH ha-1 nesta operação. Se realizado mecanicamente com separador pneumático, serão necessários para o beneficiamento apenas 208 DH ha-1.

Esta pesquisa objetivou avaliar os componentes de produção e a composição química quantitativa e qualitativa de macela em diferentes épocas de colheita.

\section{MATERIAL E MÉTODOS}

O trabalho foi desenvolvido na Universidade Federal do Ceará, em Fortaleza. O solo é do tipo Argissolo, cuja análise das características físico-químicas foi: $\mathrm{P}=138,2 \mathrm{mg} \mathrm{dm}^{-3} ; \mathrm{K}=1,40 \mathrm{mg}$ $\mathrm{dm}^{-3} ; \mathrm{Ca}=34 \mathrm{mg} \mathrm{dm}^{-3} ; \mathrm{Mg}=33 \mathrm{mg}$ $\mathrm{dm}^{-3}$ e $\mathrm{H}+\mathrm{Al}=13,0 \mathrm{mmol}_{\mathrm{c}} \mathrm{dm}^{-3} ; \mathrm{pH}$ em solução $\mathrm{CaCl}_{2}=6,0$; areia grossa $=525,5$ $\mathrm{g} \mathrm{kg}^{-1}$; areia fina $=333 \mathrm{~g} \mathrm{~kg}^{-1}$; silte $=$ 79,7 g kg ${ }^{-1}$; argila $=350$ g kg-1 e matéria orgânica $=20,9 \mathrm{~g} \mathrm{dm}^{-3}$.

As mudas foram produzidas por sementes, em bandejas de 72 células contendo Plantagro ${ }^{\circledR}$ como substrato, em casa-de-vegetação, sob nebulização intermitente. Decorridos 52 dias da semeadura, efetuou-se o transplantio para o local definitivo. Os tratamentos consistiram de sete épocas de colheitas realizadas 75; 85; 95; 105; 115; 125 e 135 dias após o transplantio (DAT), dispostas em um delineamento em blocos ao acaso, com quatro repetições. A parcela (1,20 m x 4,00 m) foi constituída por 12 plantas, espaçadas de 0,50 entre elas e 1,00 m entre fileiras. Para avaliação, foram consideradas duas plantas na área útil de cada parcela (1,00 m x 0,50 m).

Os tratos culturais foram: adubação de fundação com o adubo orgânico Vitasolo ${ }^{\circledR}\left(2,4 \mathrm{~kg} \mathrm{~m}^{-2}\right)$, cobertura morta com palha de carnaúba, quatro capinas manuais, duas aplicações de Biocontrol ${ }^{\circ}, 47$ e 54 DAT, na dose de 5,0 ml L-1 d’água, e irrigações diárias por microaspersão, exceto nos dias chuvosos. Nas épocas indicadas como tratamento, procedeu-se ao arranquio manual das plantas. A seguir, retirou-se a terra aderida às raízes, com posterior secagem das plantas íntegras a $40^{\circ} \mathrm{C}$ por 72 h. Em seguida os capítulos foram separados manualmente e ventilados em soprador pneumático. Depois que os capítulos foram destacados das plantas, procedeu-se à secagem de caules, folhas e raízes, em estufa a $80^{\circ} \mathrm{C}$ por $24 \mathrm{~h}$.

Foram avaliadas as características: altura da planta $(\mathrm{cm})$; massa seca de caules e folhas ( $\mathrm{t} \mathrm{ha}^{-1}$ ); produção de capítulos (t ha-1); índice de colheita (\%); relação percentual entre a massa seca dos capítulos e a massa seca da parte aérea, adaptada da metodologia proposta por Costa et al. (1985); rendimento dos extratos etanólico (REE) e clorofórmico (REC), calculados com base na massa seca das partes aérea, radicular e capítulos florais, conforme Ferri (1996); rendimento de óleo essencial dos capítulos $\left(\mathrm{L} \mathrm{ha}^{-1}\right.$ ) em cada colheita. Uma amostra de capítulos foi submetida à hidrodestilação, em aparelho doseador tipo Clevenger, modificado por Goottlieb (Gottlieb \& Magalhães, 1960), para extração do óleo essencial e cálculo do rendimento; teores de acetato de trans-pinocarveíla, $\beta$-pineno e acetato de mirtenila (esses constituintes majoritários presentes no óleo essencial dos capítulos florais) foram determinados segundo Adams (2001)).

Os dados foram submetidos à análise de regressão e a significância dos parâmetros do modelo foi analisada pelo teste t (Ribeiro Júnior, 2001).

\section{RESULTADOS E DISCUSSÃO}

A altura máxima das plantas (Figura 1a) foi de 39,3 cm, 107 dias após o transplante, indicando que a planta cessou o seu crescimento unidirecional nessa época. Constatou-se incremento diário de $0,05 \mathrm{t} \mathrm{ha}^{-1}$ de massa seca do caule e folhas, equivalente a 2,5 g planta $^{-1}$ (Figura 1b). Cruz (1999) registrou acúmulo diário de 0,03 t ha-1 de massa seca de hortelã-rasteira (Mentha x villosa Huds), em sete colheitas semanais, a partir de 90 dias após o plantio, na estação chuvosa de Pentecoste, Ceará. No entanto, na hortelã-japonesa (Mentha arvensis L. var. piperascens Holmes), Mattos (2000) verificou que não houve influência da época de colheita na produção de massa seca, tanto na estação seca (2,0 t $\left.\mathrm{ha}^{-1}\right)$, quanto na chuvosa $\left(2,3 \mathrm{t} \mathrm{ha} \mathrm{a}^{-1}\right)$. Por sua vez, a produção de capítulos (Figu- 


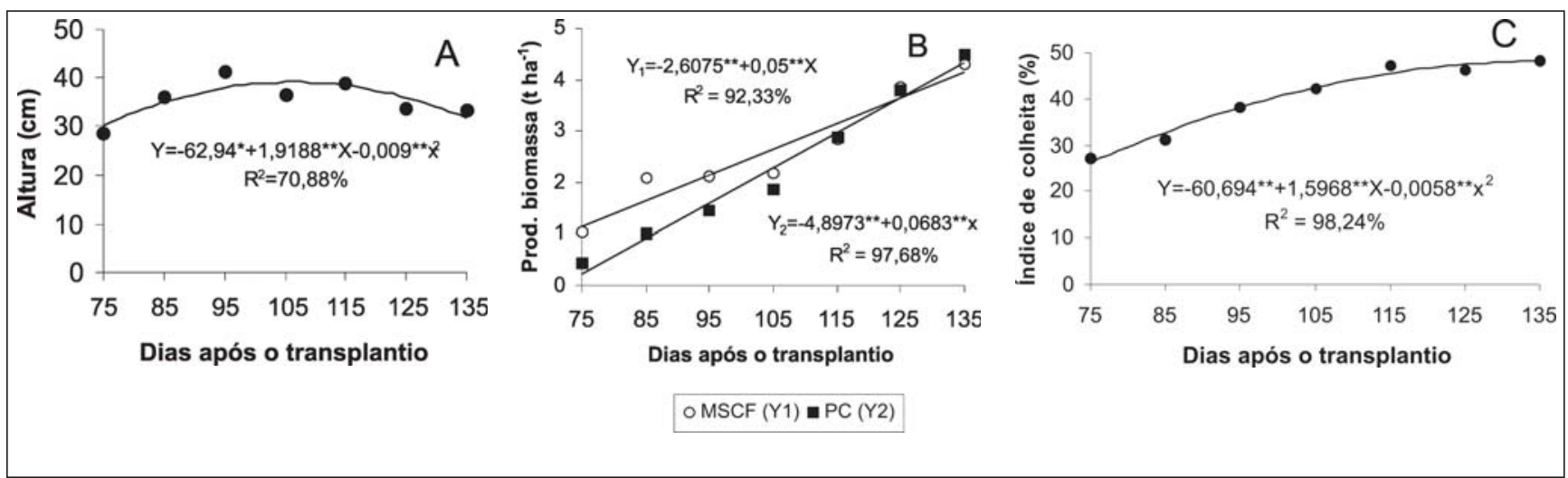

Figura 1. Altura (a), massa seca de caule + folhas $\left[\mathrm{MSCF}=\mathrm{Y}_{1}\right.$, (b)], produção de capítulos [PC=Y; (b)] e índice de colheita (c) de macela em diferentes épocas (height (a), dry mass of stem + leaves $\left[\mathrm{MSCF}=\mathrm{Y}_{1}\right.$, (b)], flower buds production $\left[\mathrm{PC}=\mathrm{Y}_{2}\right.$; (b) and harvesting index (c) of Egletes viscosa in different harvesting dates). Fortaleza, UFC, 2003.

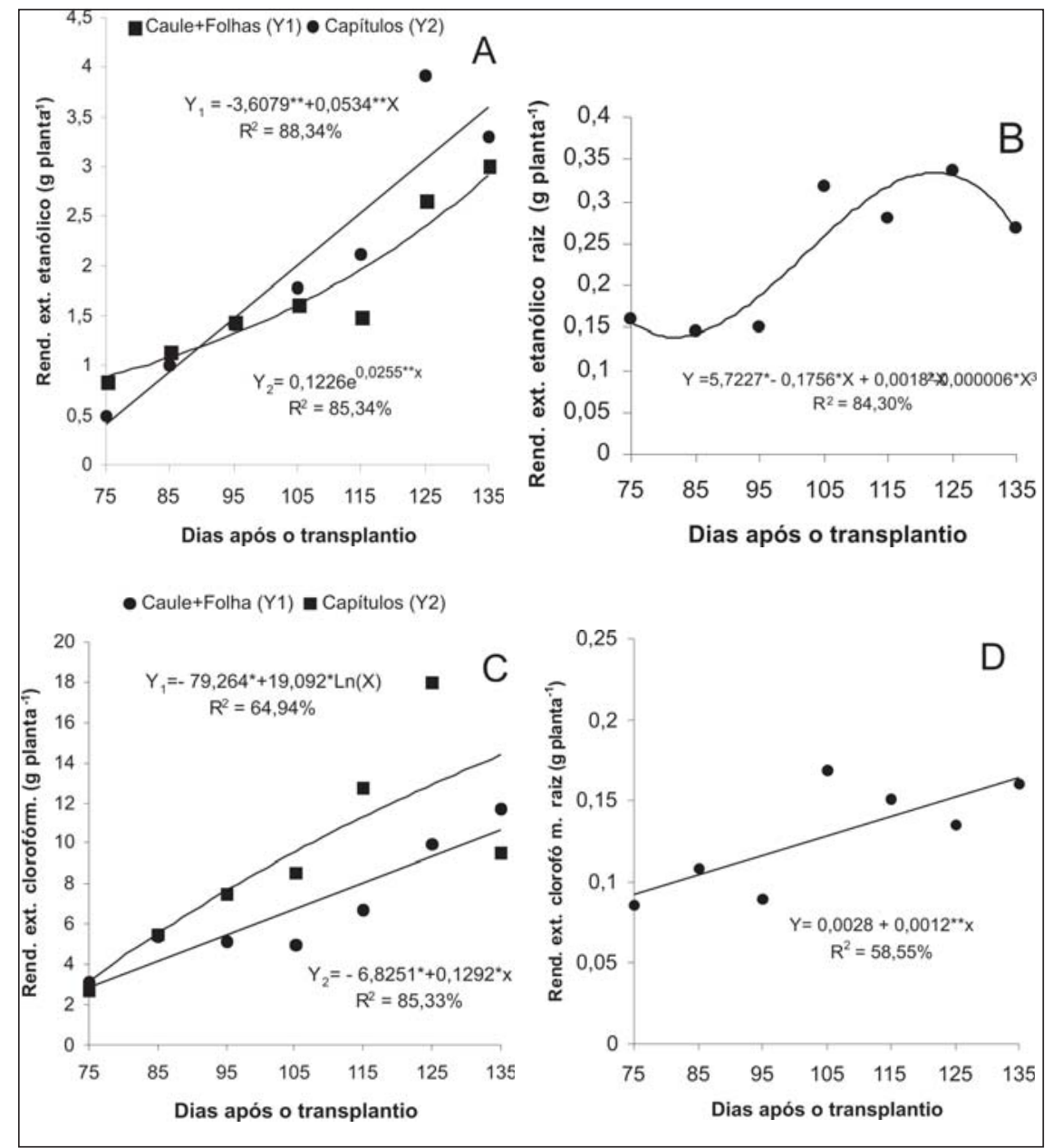

Figura 2. (a) Rendimentos dos extratos etanólicos de caule + folhas $\left(\mathrm{Y}_{1}\right)$, capítulos florais $\left(\mathrm{Y}_{2}\right)$ e (b) raízes; (c) rendimentos de extratos clorofórmicos de caule com folhas $\left(\mathrm{Y}_{1}\right)$, capítulos florais $\left(\mathrm{Y}_{2}\right)$ e (d) raízes de macela em diferentes épocas de colheita ((a) yielding of ethanol extracts from stems + leaves $\left(\mathrm{Y}_{1}\right)$, flower buds $\left(\mathrm{Y}_{2}\right)$ and (b) roots; (c) yielding of chloroform extracts from stems + leaves $\left(\mathrm{Y}_{1}\right)$, flower buds $\left(\mathrm{Y}_{2}\right)$ and (d) roots of Egletes viscosa in the different harvesting dates). Fortaleza, UFC, 2003.

ra 1b) apresentou aumento diário de 0,068 t ha $^{-1}$ ou 3,4 g planta ${ }^{-1}$, durante as diferentes épocas de colheita estudadas.
Nas três últimas colheitas (115, 125 e 135 DAT), a produção de capítulos (Figura 1b) foi superior (2,6; 3,4 e 6,7 t ha-1) às demais. Uma característica peculiar dessa espécie é a maturação desuniforme dos capítulos florais, conforme já tinha sido identificado pelos autores em trabalho anterior (Bezerra et al., 2002).

O índice de colheita (IC) máximo observado (48,27\%) ocorreu 135 DAT (Figura 1c). Esse índice expressa a eficiência na translocação dos produtos da fotossíntese para os órgãos de importância econômica; no caso da macela os capítulos florais. Nas quatro últimas colheitas, os índices de colheita situaram-se no intervalo de 42,26 - 48,27\%, indicando que, nesses períodos as plantas foram mais eficientes na translocação dos assimilados da fonte para o dreno (inflorescências).

O rendimento do extrato etanólico (REE) (Figuras 2a e 2b) teve picos 125 dias após o transplantio (DAT) para os capítulos (3,92 g planta $\left.^{-1}\right)$ e raízes $(0,34$ g planta $\left.^{-1}\right)$ e, 135 DAT, para a parte aérea $\left(3,02 \mathrm{~g} \mathrm{planta}^{-1}\right)$. O rendimento do extrato clorofórmico (REC) apresentou padrões distintos de variação (Figuras 2c e 2d). Os valores máximos observados ocorreram 105 DAT para as raízes (0,17 g planta $\left.^{-1}\right), 125$ DAT para os capítulos (18,02 g planta $^{-1}$ ) e 135 DAT para a parte aérea $\left(11,70\right.$ g planta $\left.^{-1}\right)$. Por ocasião do pico de produtividade da macela, registrado 110 DAT, Bezerra et al. (2002) encontraram, em quatro estádios de desenvolvimento das inflorescências, os seguintes rendimentos do extrato clorofórmico: botão floral= 36,3 kg ha-1 capítulos verdes $=99,9 \mathrm{~kg} \mathrm{ha}^{-1}$; capítulos maduros $=109,7 \mathrm{~kg} \mathrm{ha}^{-1}$ e capítulos 
secos= 142,8 kg ha-1. O máximo REC (388,7 $\mathrm{kg} \mathrm{ha}^{-1}$ ) registrado por Bezerra et al. (2002) ultrapassou apenas $28,3 \mathrm{~kg}$ $\mathrm{ha}^{-1}$ ao obtido neste experimento (360,4 kg ha ${ }^{1}$ ), o que evidencia a similaridade entre ambos.

O rendimento de óleo essencial (Figura 3a) apresentou valor máximo 135 dias após o transplantio (44,4 L ha-1). Em macela, Bezerra et al. (2002) observaram que o teor de óleo essencial dos capítulos florais variou de 0,14 a 0,29\%. Cruz (1999) constatou que a produção de óleo essencial da hortelã-rasteira foi maior na estação seca do que na chuvosa, cujos rendimentos máximos ocorreram nas colheitas realizadas 118 (12,0 L ha ${ }^{-1}$, na estação seca) e 125 dias após o plantio $\left(6,7 \mathrm{~L} \mathrm{ha}^{-1}\right.$, na estação chuvosa). Por outro lado, Mattos (2000) destaca que a hortelã-japonesa produz o máximo rendimento de óleo essencial 81 dias após o plantio nas estações seca (109 L ha-1) e chuvosa (88 L ha-1), do estado do Ceará. Tais resultados demonstram que a época de colheita influencia o rendimento de óleo essencial de espécies aromáticas.

Os teores de acetato de transpinocarveíla (Figura 3b) nos capítulos situaram-se no intervalo de 52,3 a 73,5\%, apresentando redução de 13,3\% entre as colheitas realizadas de 75 a 95 dias após o transplantio (DAT) e uma estabilização em torno de 53,3\% nas colheitas efetuadas entre 115 e 135 DAT. O teor de acetato de mirtenila nos capítulos (75-135 DAT) manteve-se estável

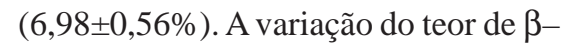
pineno nos capítulos (Figura 3b) apresentou amplitude total de 22,0\% (19,5 a $41,5 \%$ ) com dois patamares, o primeiro de 85 a 105 dias após o transplante (31,8 $\pm 1,72 \%)$ e o segundo, de 115 a 135 DAT (49,2 $\pm 1,15 \%)$.

Concluiu-se que a produção de biomassa e de capítulos florais de macela cresceu linearmente com o avanço das épocas de colheita e que caule, folhas e capítulos foram detentores de maiores rendimentos de extratos etanólico e clorofórmico que as raízes. O maior rendimento de óleo essencial das inflorescências e o maior índice de colheita foram registrados 135 dias após o transplantio. Os constituintes majoritários do óleo essencial (acetato de trans-

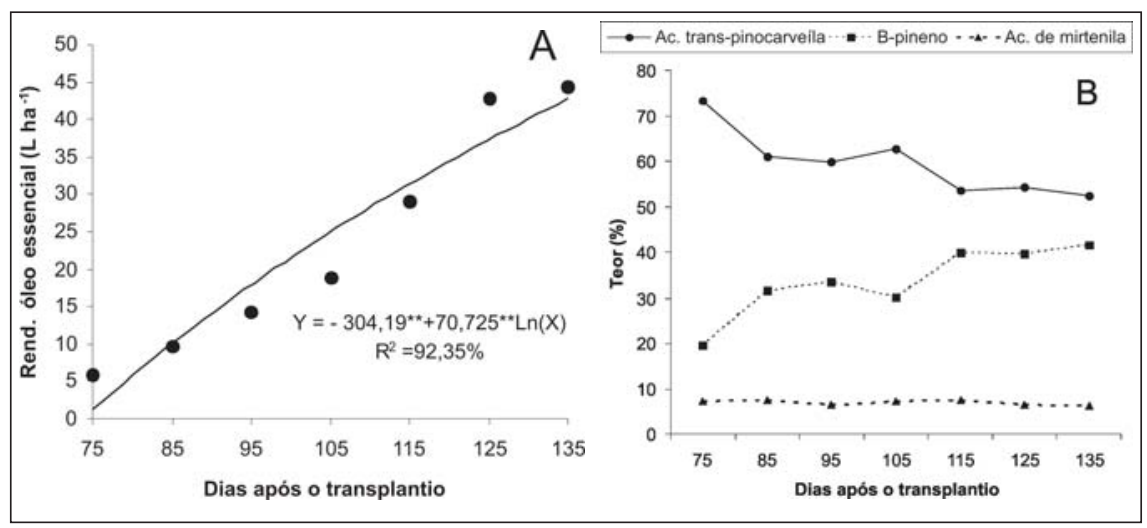

Figura 3. Rendimento de óleo essencial (a) e variação dos constituintes majoritários do óleo essencial dos capítulos florais (b) de macela, durante sete épocas de colheita (essential oil yieldings (a) and variation of the major components of the essential oil from flower buds (b) of Egletes viscosa during seven harvesting dates). Fortaleza, UFC, 2003.

pinocarveíla, acetato de mirtenila e $\beta$ pineno) apresentaram padrões distintos de variação durante as épocas de colheita.

\section{AGRADECIMENTOS}

\section{À CAPES/PICDT, pela concessão} da bolsa para realização do curso; ao CNPq/PRONEX, pelo apoio financeiro para realização das análises químicas e aos discentes Francisco José Carvalho Moreira, Fred Denílson Barbosa da Silva, Társio Thiago Lopes Alves e Marciano Góes Moreira, pelo apoio na condução do ensaio.

\section{REFERÊNCIAS}

ADAMS RP. 2001. Identification of essential oil components by gas chromatography/ quadrupole mass espectrocopy. Carol Stream: Allured Publishing Corporation. 456p.

BARROSO GM; PEIXOTO AL; ICHASO CLF; COSTA CG; GUIMARÃES EF; LIMA HC. 1991. Sistemática de angiospermas do Brasil. Viçosa: UFV/Imprensa Universitária. v. 3, p. 237-311.

BEZERRA AME; FREITAS JBS; CUNHA AN; MEDEIROS FILHO S; SILVEIRA ER. 2002. Germinação de sementes e época adequada de colheita dos capítulos florais de macela (Egletes viscosa). Revista Brasileira de Plantas Medicinais 4: 7-11.

CORRÊA MP. 1984. Dicionário das plantas úteis do Brasil e das exóticas cultivadas. Rio de Janeiro: MA/IBDF. p.19, v.5.

CORRÊA JUNIOR C; MING LC; SCHEFFER MC. 1991. Cultivo de plantas medicinais, condimentares e aromáticas. Curitiba: SEAB/ EMATER. 162p.

COSTA JGC; SHIBATA JK; COLIN SM. 1985. Índice de colheita em feijoeiro comum. Pesquisa Agropecuária Brasileira 20: 737-739.
CRUZ GF. 1999. Desenvolvimento de sistema de cultivo para hortelã-rasteira (Mentha $\mathrm{x}$ villossa Huds.), Fortaleza: UFC. 35p. (Tese mestrado).

FERRI PH. 1996. Química de produtos naturais: métodos gerais. In: DISTASI LC (org.). Plantas medicinais: arte e ciência. Um guia de estudo interdisciplinar. São Paulo: Editora UNESP. p.109-128.

GOTTLIEB OR; MAGALHÃES MT. 1960. Modified distillation trap. Chemist Analyst 49: 114.

LORENZI H; MATOS FJA. 2002. Plantas medicinais no Brasil: nativas e exóticas cultivadas. Nova Odessa: Instituto Plantarum. 544p.

MARTINS ER; CASTRO DM; CASTELLANI DC; DIAS JE. 1995. Plantas medicinais. Viçosa: UFV - Imprensa Universitária. 220p.

MATOS FJA. 2000. Plantas medicinais: guia de seleção e emprego de plantas usadas em fitoterapia no Nordeste do Brasil. 2.ed. Fortaleza: Imprensa Universitária. 344p.

MATTOS JKA. 1996. Plantas medicinais: aspectos agronômicos. Brasília: Edição do Autor. 51p.

MATTOS SH. 2000. Estudos fitotécnicos da Mentha arvensis L. var. piperacens Holmes como produtora de mentol no Ceará. Fortaleza: UFC. 114p. (Tese doutorado).

MOREIRA FC; ALVES TTL; BEZERRA AME; MEDEIROS FILHO S. 2002. Colheita, secagem e beneficiamento dos capítulos florais de macela. In: ENCONTRO UNIVERSITÁRIO DE INICIAÇÃO À PESQUISA, 20., 2002, Fortaleza. Resumos... Fortaleza: UFC/PRPPG. (Resumo 981).

RIBEIRO JÚNIOR JI. 2001. Análises estatísticas no SAEG. Viçosa: UFV. 301p.

SILVEIRA ER; PESSOA ODL. 2005. Constituintes micromoleculares de plantas do nordeste com potencial farmacológico: com dados de RMN ${ }^{13} \mathrm{C}$. Fortaleza: Expressão Gráfica e Editora. 216p.

VON HERTWIG IF. 1991. Plantas aromáticas e medicinais: plantio, colheita, secagem, comercialização. 2 ed. São Paulo: Ícone. 414p. 